\title{
Evaluation of Fast Mobility Particle Sizer (FMPS) for Ambient Aerosol Measurement
}

Aerosol and Air Quality Research

\section{OPEN ACCESS}

Received: August 17, 2020

Revised: January 5, 2021

Accepted: January 9, 2021

${ }^{*}$ Corresponding Author:

heejung@engr.ucr.edu

\section{Publisher:}

Taiwan Association for Aerosol Research

ISSN: $1680-8584$ print

ISSN: 2071-1409 online

(c) Copyright: The Author(s).

This is an open access article distributed under the terms of the Creative Commons Attribution License (CC BY 4.0), which permits unrestricted use, distribution, and reproduction in any medium, provided the original author and source are cited.

\author{
Yue Lin ${ }^{1,2}$, Liem Pham ${ }^{1,2}$, Xiaoliang Wang ${ }^{3}$, Roya Bahreini ${ }^{4}$, Heejung S. Jung ${ }^{1,2^{*}}$ \\ ${ }^{1}$ Department of Mechanical Engineering, University of California Riverside, CA 92521, USA \\ ${ }^{2}$ CE-CERT (College of Engineering-Center for Environmental Research and Technology), \\ University of California, Riverside, CA 92507, USA \\ ${ }^{3}$ Desert Research Institute, Reno, NV 89512, USA \\ ${ }^{4}$ Department of Environmental Science, University of California Riverside, CA 92521, USA
}

\section{ABSTRACT}

Fast Mobility Particle Sizer (FMPS) size distribution measurements with different inversion matrices were compared with the Scanning Mobility Particle Sizer (SMPS) for ambient aerosols sampled from a background location in Riverside, CA in this study. The FMPS-compact matrix showed the best agreement with SMPS for particle concentration in the size ranges of 9-359 nm and 9-100 nm (for ultrafine particles). The FMPS-compact matrix also showed the best agreement with the SMPS for mode diameter. All FMPS inversion matrices showed size-dependent discrepancies compared with the SMPS. Measurement of the non-volatile fraction of ambient aerosol downstream of a catalytic stripper showed that the FMPS-compact matrix agreed best with the SMPS with the FMPS over SMPS linear regression slope of 0.99-1.00 for particle concentrations. This is likely due to the restructuring of soot during the removal of volatile coating. This study showed that the soot and compact matrices are insufficient for ambient aerosol measurement. Challenges remain for FMPS measurements when particle morphologies are not known a priori or when they are different from near spherical shape or aggregate structure.

Keywords: Particle size distribution, Inversion matrix, Ambient particles, Fractal dimension, Fast Mobility Particle Sizer

\section{INTRODUCTION}

Ever since the algorithm for the Scanning Mobility Particle Sizer (SMPS) was first introduced by Wang and Flagan (1990), it has served as a standard for particle mobility size distribution measurement. While the SMPS is relatively accurate and well characterized, the long scanning time ( 2 $\mathrm{min}$ ) limits its application to highly dynamic and transient phenomena. A fast SMPS was introduced by Shah and Cocker (2005) using a radial differential mobility analyzer (DMA) and a mixing type condensation particle counter (CPC). It can measure from 5 to $98 \mathrm{~nm}$ range as fast as $0.4 \mathrm{~Hz}$. TSI also developed a fast SMPS (Model 3938), which uses both the short and long column DMAs. It can measure from 1 to $1000 \mathrm{~nm}$ size range and one fast scan takes less than 15 seconds (Erickson and Quant, 2011). In both cases, the scanning nature to classify particles leads to a trade-off between the sizing accuracy and time resolution. A recent study accounted for DMA transfer function distortion during fast scans as well as the time delay in plumbing and detector. As a result, it improves the accuracy of the data inversion from fast SMPS scans (Mai and Flagan, 2018; Mai et al., 2018). Another recently developed a fast integrated mobility spectrometer (FIMS) that uses an electric field to separate particles, subsequently grows particles by alcohol or water condensation, and measures size distributions using a high speed CCD camera (Olfert et al., 2008). This instrument is still evolving and the latest FIMS can measure 10-600 nm every second (Wang et al., 2018). The Fast Mobility Particle Sizer (FMPS) from TSI is another fast size distribution measurement instrument; it can simultaneously measure mobility-classified particles 
for the size range from 5.6 to $560 \mathrm{~nm}$ every second by an array of 22 electrometers. The FMPS uses the same hardware and data inversion algorithm as the Engine Exhaust Particle Sizer (EEPS), except that the FMPS reports data up to $1 \mathrm{~Hz}$ while the EEPS reports data up to $10 \mathrm{~Hz}$. These two instruments are treated the same in this paper.

Wang et al. (2016a, b) summarized several studies that compared size distribution measured by the SMPS and EEPS with the default inversion matrix. For near spherical particles, the FMPS agrees with the SMPS for particles $\lesssim 50 \mathrm{~nm}$ but underestimates sizes and concentrations for particles $\gtrsim 75 \mathrm{~nm}$. For non-spherical particles such as soot, the discrepancies are larger. The FMPS shows smaller mode diameters, narrower distributions, and higher total number concentrations than the SMPS. The conversion of FMPS electrometer current to size distribution utilizes the inversion matrix, which accounts for particle transport losses, charge distribution, and current detection by the electrometers. The default FMPS inversion matrix was based on a combination of theoretical modeling and limited experiments with compact-shape particles. However, the amount of charge acquired in the FMPS unipolar charger depends on particle shape. For example, particles with lower fractal dimensions acquire 20-30\% more charges than those with higher fractal dimensions (Oh et al., 2004; Shin et al., 2010). Therefore, different FMPS inversion matrices are needed to account for different particle shapes.

Recently, two inversion matrices, referred to as the compact and soot matrices, were developed by calibrating the FMPS with two extreme cases of shapes (near spherical shape and soot aggregates) to improve the accuracy of FMPS measurement. The compact matrix (Wang et al., 2016a) was developed using lab-generated near-spherical particles of sucrose, poly- $\alpha$-olefin oil (PAO) and sodium chloride ( $\mathrm{NaCl}$ ), whereas the soot matrix (Wang et al., 2016b) was developed using diesel engine exhaust particles as the calibration aerosol. Direct calibration of the FMPS with particles of different shapes allows the effects of particle shape to be taken into account in the FMPS data inversion. Xue et al. $(2015,2016)$ reported significantly improved agreement between the particle mass calculated from integrated particle size distribution (MIPSD) using size distributions measured by an FMPS with the soot matrix and the mass measured using the gravimetric method ( $\mathrm{MGrav}_{\mathrm{G}}$ ). Replacing the FMPS default matrix with the soot matrix improved the linear regression slopes of $\mathrm{M}_{\mathrm{IPSD}} / \mathrm{M}_{\mathrm{Grav}}$ from $0.45-0.57$ to $0.76-1.01$ for gasoline direct injected (GDI) vehicles over transient driving cycles. However, performances of these inversion matrices have not been evaluated for ambient aerosols. Morphology of ambient aerosols is more complex than that of aerosols from specific sources. It also varies with time and location. The soot matrix may be appropriate for measurement at near road locations while the compact matrix may be appropriate for ambient background locations dominated by secondary aerosols. This study aims to evaluate the performance of the FMPS matrices for ambient aerosols in Riverside, CA. The particles at this measurement location are known to be dominated by secondary species, especially secondary organic aerosols (SOAs) in the summer when photochemistry is active. With an abundance of SOA, internally mixed particles are expected to dominate in the $5.6-560 \mathrm{~nm}$ size range (Lin et al., 2018). The measurement was conducted in March, when SOAs were moderately abundant. Performance of the matrices was also evaluated for ambient particles before and after removing the volatile fraction, using a catalytic stripper.

\section{EXPERIMENT SETUP}

Measurements were conducted at the University of California, Riverside campus $\left(33.974892^{\circ}\right.$, $-117.326184^{\circ}$ ) on March 8-9, 2017. This sampling site was located on the second floor of the Geology building, which was $\sim 0.55 \mathrm{~km}$ away from the highway State Route 60 and $3.6 \mathrm{~km}$ away from the Highway 91 . The site was away from other major anthropogenic sources. The sampling inlet was $\sim 5.5 \mathrm{~m}$ above the ground. As shown in Fig. 1, the aerosol first passed through a residence chamber with a residence time of $\sim 140$ seconds to dampen the change of particle size distributions considering the relatively slow response of the SMPS. To make particle diffusional losses similar, conductive sampling tubing of the same inner diameter was used and the lengths of the tubes were adjusted such that the transit time of aerosol from the residence chamber to each instrument was the same. Alternatively, a catalytic stripper (CS) working at $300^{\circ} \mathrm{C}$ was installed upstream of the FMPS and SMPS to remove the volatile fraction of ambient aerosol. The FMPS and SMPS 


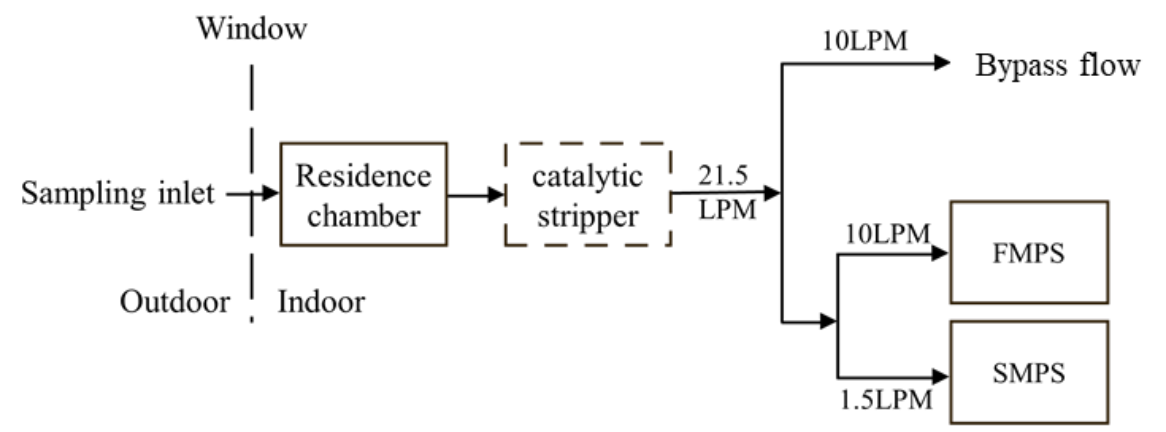

Fig. 1. Schematic diagram of ambient aerosol measurement setup.

simultaneously measured the unconditioned particle size distributions without the CS from 12:00 to 22:00 on March 8, 2017 and thermally-conditioned particle size distributions with the CS from 0:00 to 18:00 on March 9, 2017. The FMPS measured particle size distributions (PSDs) at 1-second interval in the mobility diameter $\left(d_{m}\right)$ range of $5.6-560 \mathrm{~nm}$ while the SMPS measured PSDs every 2 minutes from 9 to $359 \mathrm{~nm}$. Both FMPS and SMPS size distributions were averaged every 10 minutes for comparison. More detailed information regarding operating conditions and software features are summarized in Table 1.

\section{RESULT AND ANALYSIS}

Time-resolved particle size spectra from the SMPS and FMPS using different FMPS inversion matrices measured during 12:00-22:00 of March 8, 2017 are shown in Fig. 2. SMPS size spectra showed that the nucleation mode $(\leqslant 20 \mathrm{~nm}$ ) became prominent starting from 12:20. The nanoparticles appear to be from a regional scale nucleation event that were transported to the sampling site with northerly winds (Fig. S1). Between 13:30 and 14:30 particle number concentrations reached its peak concentrations with mode diameters ranging from 9 to $18 \mathrm{~nm}$. After 14:30, the mode diameter remained constant and nucleation mode concentrations decreased gradually. Changes in the meteorological conditions suggest a transition period between 17:00-20:00 when wind direction changed to southeasterly. The temperature and relative humidity also changed significantly (Fig. S1). These trends indicate a distinct shift in the source of air masses transported to the site by 20:00. As a result, after 20:00, particle size distributions were unimodal with mode diameters around $50 \mathrm{~nm}$. Given the wind direction, location of the nearby highways to the south/southeast of campus, and the typical traffic-related aerosol size distributions (Voigtländer et al., 2006), it is likely that the site was influenced by vehicular emissions after 20:00. Under a constant influence of sources, both coagulation and enhanced partitioning of semivolatile components at lower nighttime temperatures could contribute to the nighttime particle growth (Stolzenburg et al., 2005). However, we do not believe the larger particles observed after 20:00 are related to the growth of nucleation mode particles observed before 17:00 given the change in the wind direction during the transition period. These trends, along with 12-hr back-trajectory HYSPLIT (HYbrid SingleParticle Lagrangian Integrated Trajectory, https://www.arl.noaa.gov/hysplit/hysplit/) analysis

Table 1. Summary of instrument operation setting and software.

\begin{tabular}{llllll}
\hline Instrument & Model & $\begin{array}{l}\text { Sample flow } \\
\text { rate (LPM) }\end{array}$ & $\begin{array}{l}\text { Sheath flow } \\
\text { rate (LPM) }\end{array}$ & $\begin{array}{l}\text { Particle } \\
\text { detection } \\
\text { range (nm) }\end{array}$ & Software \\
\hline SMPS & $\begin{array}{l}\text { Classifier: } 3080 \\
\text { DMA: } 3081 \text { CPC: } 3776\end{array}$ & 1.5 & 7.5 & $9-359$ & $\begin{array}{l}\text { Aerosol Instrument Manager (ver. 9.0.0) } \\
\text { Particle diffusion correction } \\
\text { Multiple charge correction }\end{array}$ \\
FMPS & 3091 & 10 & 40 & $5.6-560$ & $\begin{array}{l}\text { FMPS software (3.2.1.1) } \\
\text { default matrix, compact matrix, soot } \\
\text { matrix. }\end{array}$ \\
\hline
\end{tabular}



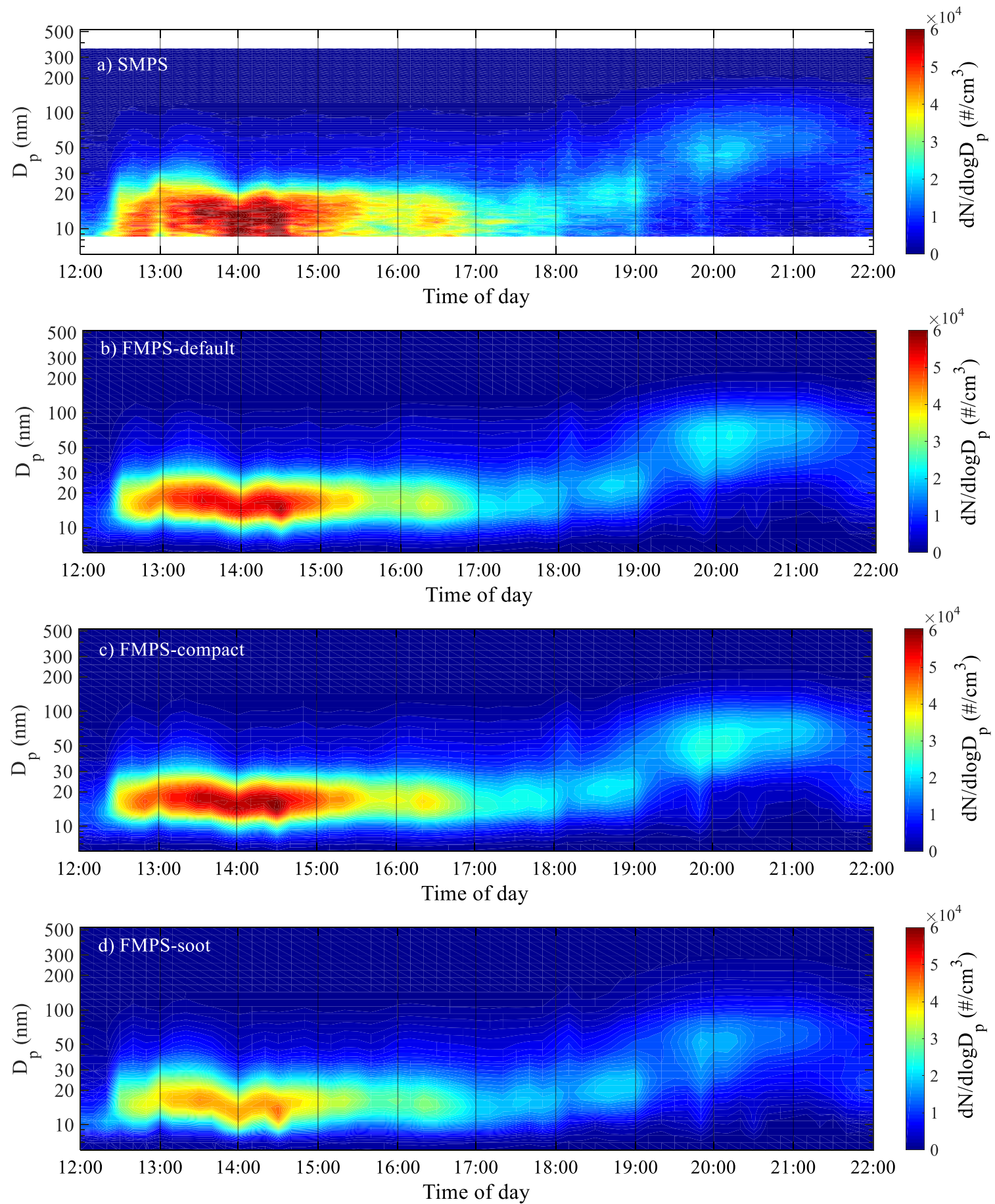

Fig. 2. Particle size spectra for: (a) SMPS; (b) FMPS with default matrix; (c) FMPS with compact matrix; and (d) FMPS with soot matrix during 12:00-22:00 of March 8, 2017. Note white empty space below $9 \mathrm{~nm}$ and above $359 \mathrm{~nm}$ was due to lower and upper end size range limits of the SMPS.

(using 3-km resolution meteorological fields as input), indicate a distinct shift in the source of air masses transported to the site by 20:00 that could have carried different types and concentrations of atmospheric trace gases and aerosols (Fig. S1 panel $d$ and e). Panels b-d in Fig. 2 show FMPS size spectra processed with the three different inversion matrices. Qualitatively, the FMPS appeared to show similar trends with the SMPS. However, the FMPS soot matrix (Fig. 2(d)) reported much lower nucleation mode concentrations than the SMPS between 13:00 and 15:00. On the other hand, the FMPS default (Fig. 2(b)) and compact (Fig. 2(c)) matrices showed higher accumulation mode $(\sim 30-300 \mathrm{~nm})$ particle concentrations during 19:40-21:00. 
Total particle number concentrations from the SMPS and FMPS for the size range of 9-359 nm are compared in Fig. 3(a). The SMPS number concentration reached the peak of $2.9 \times 10^{4}$ particles $\mathrm{cm}^{-3}$ at 13:40 due to the strong nucleation mode, then decreased to $1.1 \times 10^{4}$ particles $\mathrm{cm}^{-3}$ after 20:00 as the nucleation mode disappeared. All FMPS matrices showed lower concentrations than the SMPS before the wind direction transition around 18:00, while the concentrations by FMPS with default and compact matrices became similar to those by the SMPS after $\sim 19: 00$. Fig. 3(b) shows that the SMPS and FMPS concentrations with different matrices were strongly $\left(R^{2}=0.95-\right.$ 0.96) correlated. The linear regression slope increased from 0.79 by the soot matrix, 0.92 by the default matrix, to 0.97 by the compact matrix. It should be noted that the relative concentration
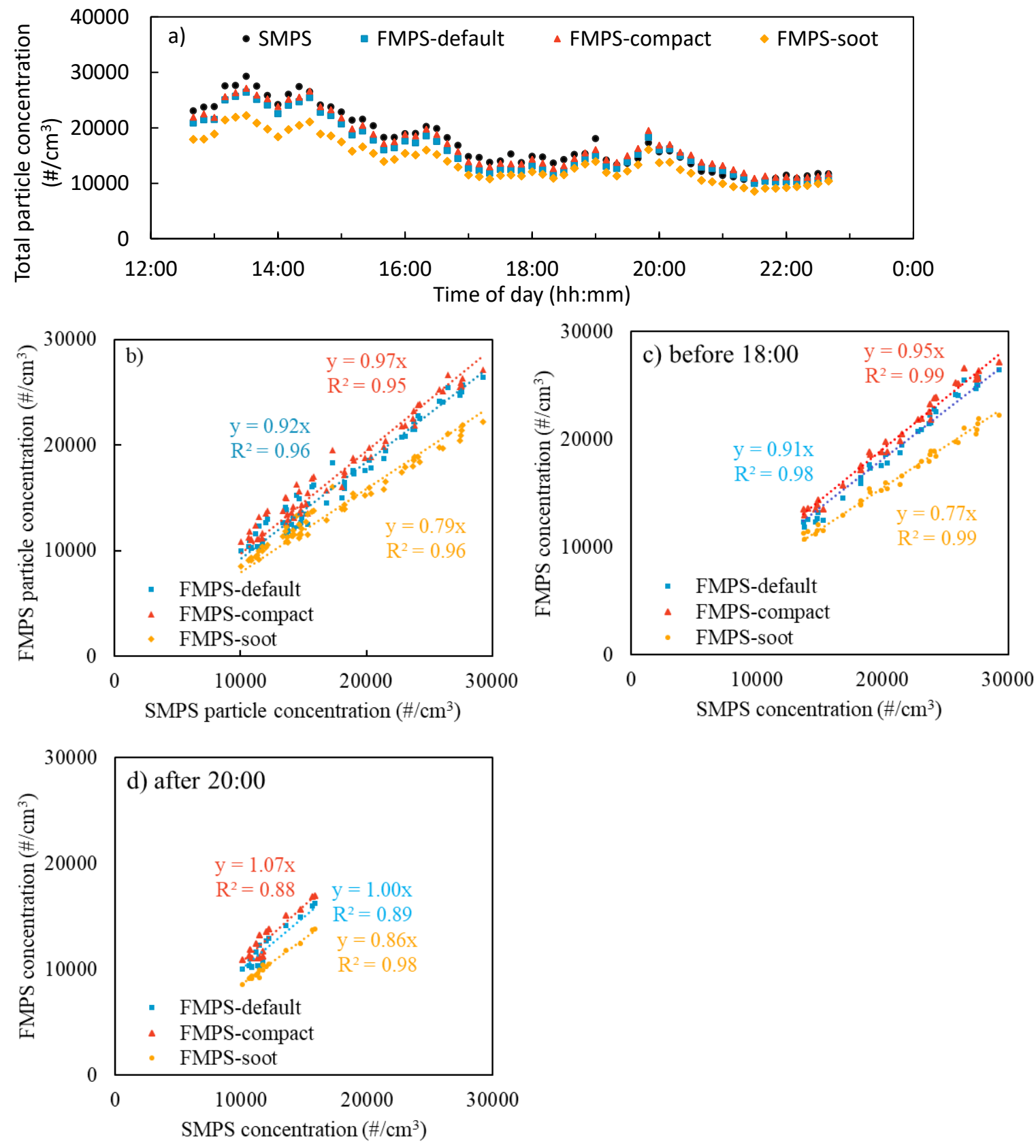

Fig. 3. (a) Time series of particle number concentration from SMPS and different FMPS inversion matrices over the overlapping measurement size range 9-359 $\mathrm{nm}$; (b) correlation of particle number concentration between SMPS and different FMPS matrices for the time period from 12:30 to 23:00; (c) correlation of particle number concentration between SMPS and different FMPS matrices for the time period from 12:30 to 18:00; and (d) correlation of particle number concentration between SMPS and different FMPS matrices for the time period from 20:00 to 23:00. 
difference between the SMPS and FMPS was nearly independent of concentration. As such, the regression was dominated by high concentrations of near spherical nucleation mode particles, resulting in the best agreement between the compact matrix and the SMPS. It is possible that the changes in particles size distribution and total concentration difference between SMPS and FMPS with different matrix after $\sim 18: 00$ were related to particle morphology change. Linear regressions between FMPS and SMPS total concentrations were performed before and after the wind direction switch, as shown in Figs. 3(c) (12:30-18:00) and 3(d) (20:00-23:00). The regression slopes increased by $\sim 0.1$ for all three matrices after the wind switch. Additional morphological measurements are needed to study the sensitivity of SMPS and FMPS measurements to particle morphology changes. Total number concentration is very sensitive to measurement uncertainties close to lower size limits of the SMPS and FMPS, especially when there is a strong nucleation mode. As pointed out by Wang et al. (2016b), both the SMPS and FMPS have higher uncertainties for particles less than $15 \mathrm{~nm}$ due to lower particle charging efficiency, higher diffusion loss, lower CPC counting efficiency, and higher electrometer noise to signal ratio as compared to larger particles. Furthermore, the FMPS matrices were not optimized for particles less than $15 \mathrm{~nm}$ size range due to difficulties in obtaining high concentrations of monodisperse particles in that size range for FMPS calibration (Wang et al., 2016a, b).

Particle concentrations in the ultrafine size range $\left(d_{m}=9-100 \mathrm{~nm}\right)$ are shown in Fig. S2. A similar trend to that in Fig. 3 was observed. This is similar to Jeong and Evan's (2009) findings who measured ambient particles $20 \mathrm{~m}$ away from a busy street and $50 \mathrm{~m}$ away from a busy traffic intersection. They compared total ultrafine particle concentrations in the range of 6-100 nm and reported that the FMPS default matrix underestimated total ultrafine particle concentrations with a FMPS to SMPS concentration ratio of 0.87 . Note the FMPS to SMPS ratio was 0.92 in the current study based on the default matrix slope in Fig. S2(b), while the soot and compact matrices had slopes of 0.79 and 0.97 , respectively. Fig. S2(c) and S2(d) report regression slopes for separate time slots namely before $18: 00$ and 20:00 respectively. Fig. S2 suggests the same information as Fig. 3.

Mode diameters are compared in Fig. 4. The SMPS mode diameter was in the range of 8.6$17.3 \mathrm{~nm}$ before 18:00 and did not change significantly. After $\sim 18: 00$, it gradually increased and reached a peak of $\sim 50 \mathrm{~nm}$ around 21:00. All FMPS matrices showed larger mode diameter than the SMPS. The compact matrix overestimated particle mode diameter by a factor of 1.15-2.48 with an average of 1.49 , the soot matrix overestimated by factor of $0.90-2.46$ with an average of 1.41 , and the default matrix overestimated by factor of 1.17-2.50 with an average of 1.51 . Regardless of matrices, FMPS mode diameters were evidently larger than SMPS by a factor larger than 2 between 16:30-18:00. Between 19:00 and 21:00, the FMPS soot matrix reported closer mode diameter to SMPS than the other two matrices. This supports our hypothesis that the particles were dominated by vehicle exhaust emissions and mostly soot that in this period, as discussed in Fig. 2. Correlations between the SMPS and FMPS mode diameters are shown in Fig. $4 \mathrm{~b}$. While the regression slopes were close to $1(0.88-1.12)$, the intercepts were significant (6.0-7.9 $\mathrm{nm})$. Default and compact matrices showed better correlation $\left(R^{2}=0.97\right.$ and 0.98 respectively) than soot matrix $\left(R^{2}=0.94\right)$. Lee et al. (2013) compared FMPS and SMPS mode diameters by measuring DMA-selected monodispersed salt particles with mobility diameter ranging from 50 to $300 \mathrm{~nm}$. They observed that $\mathrm{FMPS}_{\text {default }}=0.56 \times \mathrm{SMPS}+14.72\left(\mathrm{R}^{2}=0.99\right)$ by applying a linear fit between DMA classified diameters and the FMPS mode diameters for different salts (i.e., sodium chloride, ammonium sulfate, ammonium nitrate, and ammonium bisulfate). Zimmerman et al. (2015) conducted similar analysis as Lee et al. (2013) using PSL, sucrose, and ammonium nitrate with mobility diameter ranging from 80.6 to $523.3 \mathrm{~nm}$. They reported FMPS default $=0.58 \times$ SMPS $+25\left(R^{2}=0.96\right)$. The slopes observed by Lee et al. $(2013)$ and Zimmerman et al. (2015) are much lower and the intercepts were higher than those observed by the current study as shown in Fig. 4(b). Fig. 4(c) includes data after 20:00. Compared to Fig. 4(b) which included particles from two different air masses, Fig. 4(c) covers a much narrower size range; the regression slopes reduced and the y-intercept increased. While the regression slopes are still higher, the y-intercept of the current study in Fig. 4(c) is comparable to that of Lee et al. (2013). The mode diameter range in the current study $(10-80 \mathrm{~nm})$ is almost at the lower boundary of those by Lee et al. (2013) and Zimmerman et al. (2015). Assuming both current and previous two studies are correct, it appears the mode diameter relationship is transitioning around $100 \mathrm{~nm}$. 

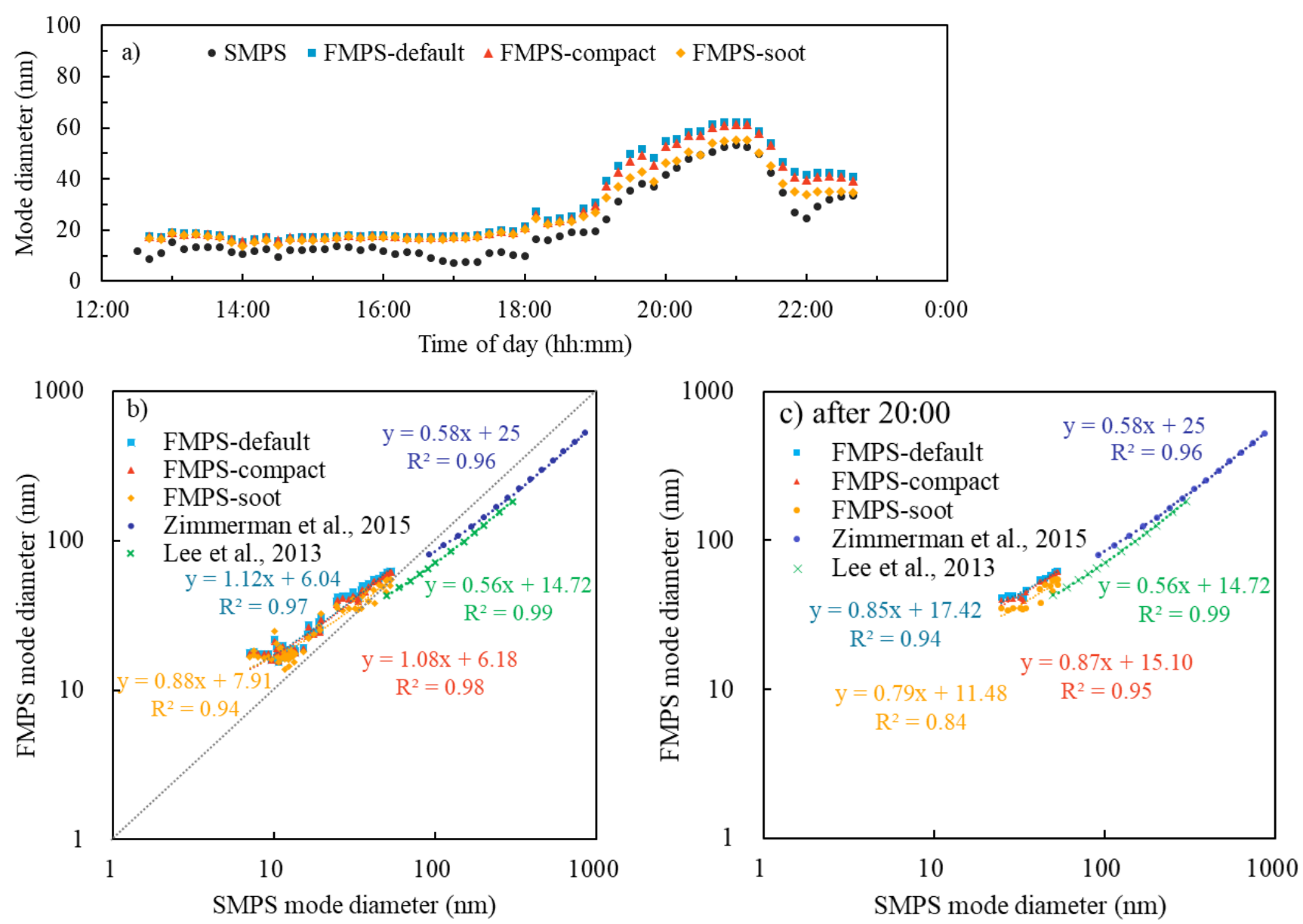

Fig. 4. (a) Time-resolved mode diameter from SMPS and FMPS; (b) correlation between SMPS and FMPS mode diameter for the time period from 12:30 to 23:00; and (c) correlation between SMPS and FMPS mode diameter for the time period from 20:00 to 23:00.

Fig. S3(a) compares the geometric mean diameters obtained from lognormal fittings of the SMPS and FMPS for ultrafine particle size range $(9-100 \mathrm{~nm})$. Overall, FMPS matrices agreed well with the SMPS until the particle size distribution change started at $\sim 18: 00$. After 18:00, similarly to Fig. 4(a), the FMPS with the soot matrix reported geometric diameters closer to the SMPS than FMPS with default or compact matrix. Correlation of geometric mean diameters from the SMPS and FMPS matrices for ultrafine particle size range $(9-100 \mathrm{~nm})$ are shown in Figs. S3(b) and S3(c). All FMPS matrices tended to overestimate the geometric mean diameter.

Two separate time periods, before and after the dramatic change in the particle size distributions around 19:00 of March 8, 2017 were chosen to compare particle size distributions between the two instruments. Figs. 5(a) and 5(b) show typical 10-min averaged particle size distributions in these two periods, depicting unimodal PSDs with mode diameter between 10$20 \mathrm{~nm}$ and $40-75 \mathrm{~nm}$, respectively. When the empirical correction protocol by Zimmerman et al. (2015) was applied to the results from the default matrix, the mode diameter was within the similar range with other FMPS matrices while the peak concentration was the highest for the 13:40-13:50 period when nucleation mode was dominant. Note this study could not carry out the last step of the Zimmerman's correction, which is normalization of concentrations using a standalone CPC measurement. Had we implemented this correction, the peak concentration could have been comparable. For the 20:00-20:10 period, when traffic related particles were dominant, the soot matrix matched with the SMPS measured PSD very well. On the other hand, the compact and default matrices as well as the empirical correction by Zimmerman et al. (2015) showed large discrepancies with the SMPS. Particles smaller than $20 \mathrm{~nm}$ deviates from the lognormal distribution suggesting possibility of an additional mode below $10 \mathrm{~nm}$. 

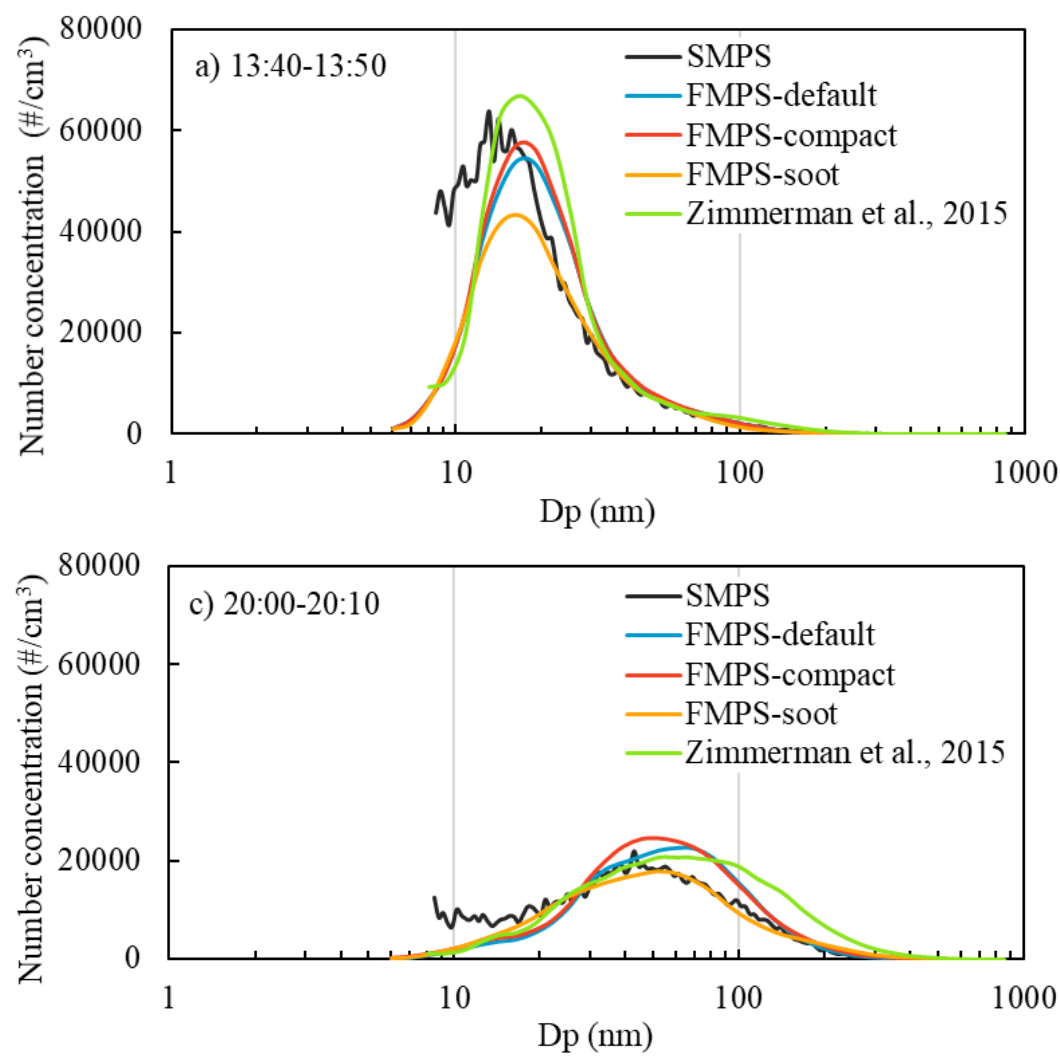

Fig. 5. Two typical PSDs averaged over 10-min time intervals of: (a) 13:40-13:50 and (b) 20:0020:10 on March 8, 2017.

For the second day of measurements, particle concentrations measured downstream of the CS with volatile fraction of particles removed are shown Fig. 6. FMPS-compact matrix agreed well with the SMPS on particle concentrations both in mobility diameter range of 9-359 nm (Fig. 6(a)) and 9-100 nm (Fig. S4(a)) with slope values of 0.95 (Figs. 6(b) and S4(b)). The FMPS with soot and default matrices underestimated particle concentration with lower slopes of 0.84 for the soot matrix and $0.74-0.75$ for the default matrix, respectively. Correlations were also obtained for the two periods before and after wind direction changes (i.e., 10:00 as shown in Fig. S5). For the size range of 9-359 $\mathrm{nm}$, the compact matrix had a slope of 0.99 before 10:00 and it dropped to 0.88 after 10:00. Similar slope drop was observed for the soot matrix, while the slope of the default matrix increased by 0.11 as shown in Figs. 6(c) and 6(d). The compact matrix had slopes closest to unity in both time periods, and the slope differences among the three matrices were smaller after 10:00 (Fig. 6(d)). A similar trend was observed for ultrafine particles in Fig. S4.

The better performance of the compact matrix is probably due to the restructuring of soot during the removal of volatile coating. Figs. 6(e) and 6(f) show two typical particle size distributions. Fig. 6(e) shows bimodal distributions of soot and the non-volatile nucleation mode particles during morning rush hours. Fig. S5 shows the wind direction during this time was from the southeast where highway 60 is located. At this early time of the day, photochemistry was not strong enough to form significant amount of secondary aerosol on the surface of soot. Therefore, we speculate that there was little to no restructuring of the soot in the CS. Further study is necessary to investigate the chemical nature of this non-volatile nucleation mode. The non-volatile nucleation mode can be either from heavy-duty diesel engines as reported by Rönkkö et al. (2007) or artifact by re-nucleation of volatile compounds downstream of CS as reported by Swanson and Kittelson (2010). Both FMPS soot matrix and SMPS captured comparable bimodality. On the other hand, the default matrix underestimated the nucleation mode concentrations significantly. Unlike soot and default matrices, the compact matrix showed intermediate inversion characteristics. In contrast, Fig. 6(f)shows the non-volatile particle size distribution in the afternoon. All the FMPS matrices showed similar degrees of underestimation of concentration compared to SMPS for 
particles $\lesssim 20 \mathrm{~nm}$, consistent with the statement by Wang et al. (2016a) that particle concentrations in this range could be underestimated by the FMPS due to difficulties in generating high concentrations of calibration aerosols of these small sizes. The FMPS compact matrix reported closer concentration in the size range of $10-40 \mathrm{~nm}$ than the other two matrices during this period.
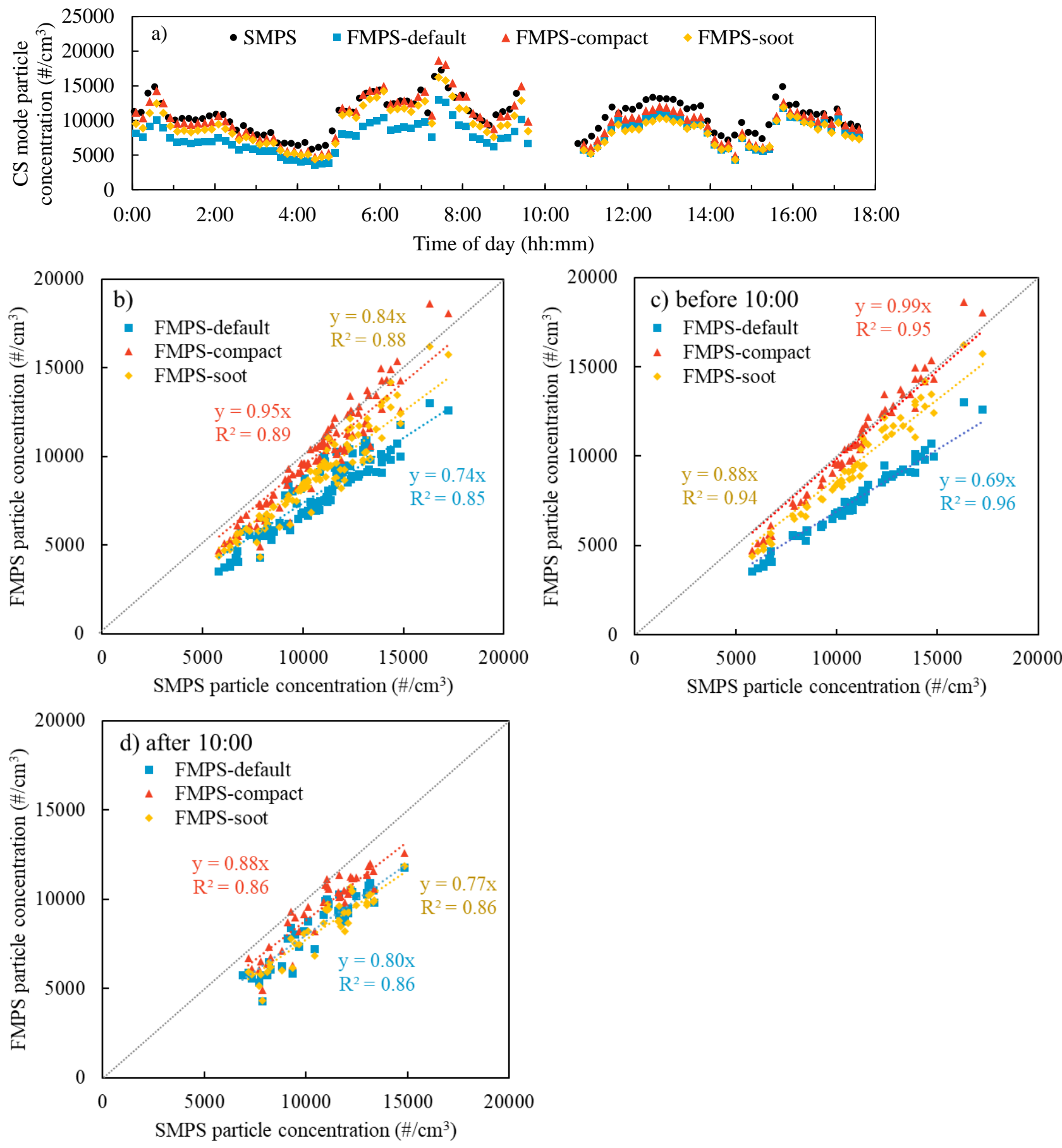

Fig. 6. (a) Time series of particle number concentration downstream of the CS measured by the SMPS and FMPS with different matrices over the overlapping measurement size range 9-359 nm during 0:00-18:00 of March 9, 2017; (b) correlation of particle number concentration downstream of the CS between SMPS and different FMPS matrices during 0:00-18:00; (c) correlation of particle number concentration downstream of the CS between SMPS and different FMPS matrices during 0:00-10:00; (d) correlation of particle number concentration downstream of the CS between SMPS and different FMPS matrices during 10:00-18:00; (e) Two typical CS mode 10-min average particle size distributions during 6:00-6:10; and (f) Two typical CS mode 10-min average particle size distributions during 15:00-15:10. 

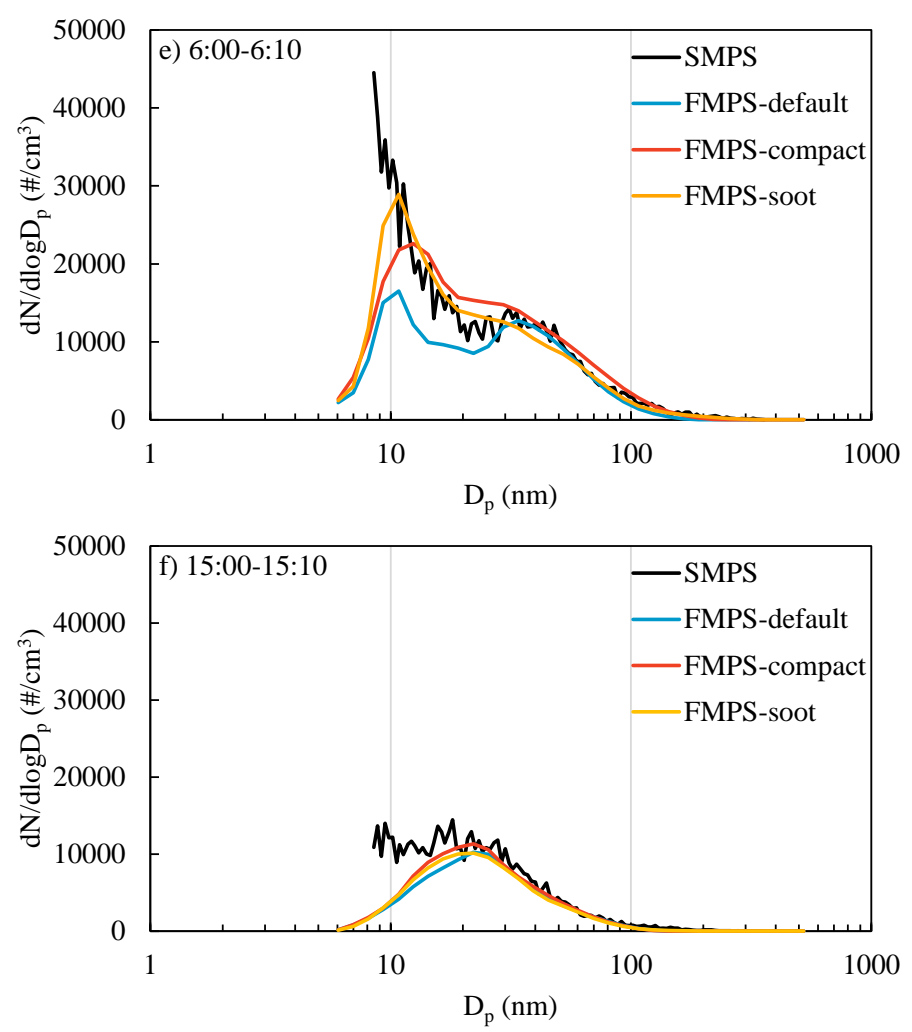

Fig. 6. (continued).

\section{CONCLUSION AND DISCUSSION}

This study evaluated the performance of different inversion matrices (default, compact and soot) for FMPS using ambient aerosols in Riverside, CA by comparing the resulting particle size distributions (PSDs) with SMPS measurements. Overall, the FMPS compact matrix agreed best with the SMPS for the current study probably due to the relatively compact morphology of the ambient particles in the region and during the season when the measurements were taken. Soot matrix showed good agreement with the SMPS for traffic related PSDs. All matrices (default, compact and soot matrix) showed some degree of discrepancy in either or some of parameters such as mode diameter, total particle concentration, and particle size distribution. Empirical corrections of the FMPS data by Lee et al. (2013) and Zimmerman et al. (2015) did not improve agreement with the SMPS for the current study.

This study has several limitations: (1) The measurement period was short ( $<2$ days) and at a single location. The FMPS performance should be further evaluated at different locations and seasons with different aerosol characteristics; (2) The SMPS was used as a reference to evaluate the FMPS performance. It is known that the SMPS has higher uncertainties in sub-15 nm size range. Therefore, including other references, such as a CPC for total number concentration, would increase the confidence in the comparison; (3) Particle chemical composition or fractal dimension were not specifically measured. Obtaining this information would provide further insights into the causes of different performances of the matrices.

The compact and soot matrices were developed using near spherical particles and diesel engine exhaust particles, representing two near extreme ranges of fractal dimension (Wang et al., $2016 a, b)$. However, their specific applicable ranges of fractal dimensions were not defined. The fractal dimensions of the majority of ambient aerosols likely lie between these two extremes. Due to the diverse nature of ambient aerosols, especially when particle morphology and charging characteristics are not known a priori, it will be difficult to determine which matrix to use or to find a single matrix that works for all scenarios. Further studies are required to test the sensitivity of FMPS size distribution measurements to morphology changes. 


\section{ACKNOWLEDGEMENT}

This research was funded by National Science Foundation (\# 1233038) and a graduate fellowship from National Center for Sustainable Transportation (NCST). The authors gratefully acknowledge the NOAA Air Resources Laboratory (ARL) for the provision of the HYSPLIT transport and dispersion model used in this publication.

\section{SUPPLEMENTARY MATERIAL}

Supplementary data associated with this article can be found in the online version at https://doi.org/10.4209/aaqr.200525

\section{REFERENCE}

Erickson, K., Quant, F. (2011). Investigation of Fast Scanning SMPS Measurements: 16s and Below. Jeong, C.H., Evans, G.J. (2009). Inter-comparison of a fast mobility particle sizer and a scanning mobility particle sizer incorporating an ultrafine water-based condensation particle counter. Aerosol Sci. Technol. 43, 364-373. https://doi.org/10.1080/02786820802662939

Lee, B.P., Li, Y.J., Flagan, R.C., Lo, C., Chan, C.K. (2013). Sizing characterization of the fast-mobility particle sizer (FMPS) against SMPS and HR-ToF-AMS. Aerosol Sci. Technol. 47, 1030-1037. https://doi.org/10.1080/02786826.2013.810809

Lin, Y., Bahreini, R., Zimmerman, S., Fofie, E.A., Asa-Awuku, A., Park, K., Lee, S.B., Bae, G.N., Jung, H.S. (2018). Investigation of ambient aerosol effective density with and without using a catalytic stripper. Atmos. Environ. 187, 84-92. https://doi.org/10.1016/j.atmosenv.2018.05.063

Mai, H., Flagan, R. C. (2018). Scanning DMA data analysis I. Classification transfer function. Aerosol Sci. Technol. 52, 1382-1399. https://doi.org/10.1080/02786826.2018.1528005

Mai, H., Kong, W., Seinfeld, J.H., Flagan, R.C. (2018). Scanning DMA data analysis II. Integrated DMA-CPC instrument response and data inversion. Aerosol Sci. Technol. 52, 1400-1414. https://doi.org/10.1080/02786826.2018.1528006

Oh, H., Park, H., Kim, S. (2004). Effects of particle shape on the unipolar diffusion charging of nonspherical particles. Aerosol Sci. Technol. 38, 1045-1053. https://doi.org/10.1080/0278682 90883324

Olfert, J.S., Kulkarni, P., Wang, J. (2008). Measuring aerosol size distributions with the fast integrated mobility spectrometer. J. Aerosol Sci. 39, 940-956. https://doi.org/10.1016/j.jaerosci.2008.06.005

Rönkkö, T., Virtanen, A., Kannosto, J., Keskinen, J., Lappi, M., Pirjola, L. (2007). Nucleation mode particles with a nonvolatile core in the exhaust of a heavy duty diesel vehicle. Environ. Sci. Technol. 41, 6384-6389. https://doi.org/10.1021/es0705339

Shah, S.D., Cocker, D.R. (2005). A fast scanning mobility particle spectrometer for monitoring transient particle size distributions. Aerosol Sci. Technol. 39, 519-526. https://doi.org/10.1080/ 027868291004652

Shin, W.G., Wang, J., Mertler, M., Sachweh, B., Fissan, H., Pui, D.Y. (2010). The effect of particle morphology on unipolar diffusion charging of nanoparticle agglomerates in the transition regime. J. Aerosol Sci. 41, 975-986. https://doi.org/10.1016/j.jaerosci.2010.07.004

Stolzenburg, M.R., McMurry, P.H., Sakurai, H., Smith, J.N., Mauldin, R.L., Eisele, F.L., Clement, C.F. (2005). Growth rates of freshly nucleated atmospheric particles in Atlanta. J. Geophys. Res. 110, D22S05. https://doi.org/10.1029/2005JD005935

Swanson, J., Kittelson, D. (2010). Evaluation of thermal denuder and catalytic stripper methods for solid particle measurements. J. Aerosol Sci. 41, 1113-1122. https://doi.org/10.1016/j.jaerosci. 2010.09.003

Voigtländer, J., Tuch, T., Birmili, W., Wiedensohler, A. (2006). Correlation between traffic density and particle size distribution in a street canyon and the dependence on wind direction. Atmos. Chem. Phys. 6, 4275-4286. https://doi.org/10.5194/acp-6-4275-2006

Wang, S.C., Flagan, R.C. (1990). Scanning electrical mobility spectrometer. Aerosol Sci. Technol. 13, 230-240. https://doi.org/10.1080/02786829008959441 
Wang, X., Grose, M.A., Avenido, A., Stolzenburg, M.R., Caldow, R., Osmondson, B.L., Chow, J.C., Watson, J.G. (2016a). Improvement of Engine Exhaust Particle Sizer (EEPS) size distribution measurement - I. Algorithm and applications to compact-shape particles. J. Aerosol Sci. 92, 95108. https://doi.org/10.1016/j.jaerosci.2015.11.002

Wang, X., Grose, M.A., Caldow, R., Osmondson, B.L., Swanson, J.J., Chow, J.C., Watson, J.G., Kittelson, D.B., Li, Y., Xue, J. (2016b). Improvement of Engine Exhaust Particle Sizer (EEPS) size distribution measurement - II. Engine exhaust particles. J. Aerosol Sci. 92, 83-94. https://doi.org/10.1016/j.jaerosci.2015.11.003

Wang, Y., Pinterich, T., Wang, J. (2018). Rapid measurement of sub-micrometer aerosol size distribution using a fast integrated mobility spectrometer. J. Aerosol Sci. 121, 12-20. https://doi.org/10.1016/j.jaerosci.2018.03.006

Xue, J., Li, Y., Wang, X., Durbin, T.D., Johnson, K.C., Karavalakis, G., Asa-Awuku, A., Villela, M., Quiros, D., Hu, S., Huai, T., Ayala, A., Jung, H.S. (2015). Comparison of vehicle exhaust particle size distributions measured by SMPS and EEPS during steady-state conditions. Aerosol Sci. Technol. 49, 984-996. https://doi.org/10.1080/02786826.2015.1088146

Xue, J., Li, Y., Quiros, D., Wang, X., Durbin, T.D., Johnson, K.C., Karavalakis, G., Hu, S., Huai, T., Ayala, A., Jung, H.S. (2016). Using a new inversion matrix for a fast-sizing spectrometer and a photoacoustic instrument to determine suspended particulate mass over a transient cycle for lightduty vehicles. Aerosol Sci. Technol. 50, 1227-1238. https://doi.org/10.1080/02786826.2016.1 239247

Zimmerman, N., Jeong, C.H., Wang, J.M., Ramos, M., Wallace, J.S., Evans, G.J. (2015). A sourceindependent empirical correction procedure for the fast mobility and engine exhaust particle sizers. Atmos. Environ. 100, 178-184. https://doi.org/10.1016/j.atmosenv.2014.10.054 